\title{
A mixed model for the effects of single gene, polygenes and their interaction on quantitative traits. 2. The effects of the nor gene and polygenes on tomato fruit softness
}

\author{
Yonatan Elkind, \\ Avigdor Cahaner and \\ Nachum Kedar
}

\author{
The Hebrew University of Jerusalem, \\ Faculty of Agriculture, Dept. of Field Crops, \\ Vegetables and Genetics, P.O. Box 12, \\ Rehovot 76100, Israel.
}

The effects of the nor gene, polygenes and their interaction on tomato fruit softness one (SF1) and nine (SF9) days after picking at "breaker" stage of ripening were studied using two experimental populations, each obtained from a different cross and comprised of F3 families derived from selfed heterozygous (nor/+) F2 plants. The results were analysed using a mixed model for a single gene, polygenes and their interaction. A multiplicative nor $\times$ polygenes interaction was detected for SF1, and it was included in the model by log transformation. The multiplicative coefficients of the nor effect on family means were $0 \cdot 76,1 \cdot 07,1 \cdot 23$, and $0 \cdot 77,1 \cdot 06,1 \cdot 22$ for nor/nor, nor $/+,+/+$, respectively, in population 1 and 2, each. "Net Polygenic Heritability" was estimated as 0.51 and 0.27 in two different populations. The corresponding multiplicative coefficients for SF9 were $0.62,1.06$ and 1.51 and 0.60 , 1.07 and 1.56 . After log transformation, a random nor $\times$ polygenes interaction was also found for SF9. It was concluded that a rather small experiment of the design used (13-21 families, 305-461 individuals) facilitated simultaneous detection of the effects of a single gene, polygenes and their interaction on quantitative traits, as well as characterization of the nature of the interaction. This provided better understanding of the genetic control, as well as improved estimates of genetic parameters than those obtained when lack of such interaction was assumed.

\section{INTRODUCTION}

Firmness and shelf life are among the most important characters of tomato fruits. Firmness has been described as a quantitative trait with continuous distribution (Al-Falluji, Trinklien and Lambeth, 1982). El-Sayed, Erikson and Tomes (1966), studied a cross between relatively soft parents and concluded that firmness 7 days after picking at the "turning stage" was controlled by one major gene and a few modifiers, with the softer parent being dominant. Al-Falluji, Trinklien and Lambeth (1982) found that the genetic control of firmness of fruits, four days after picking at the "turning stage", followed an additive-dominant polygenic model, with an average additive effect twice as large as the average dominant one.

Several ripening mutants, rin, nor and $\mathrm{Nr}$, which are inherited as single.genes, affect some or all components of the ripening process. These mutants also affect the softening of the tomato fruit during ripening (Brady et al., 1982) and their use in breeding programs for extending shelf life, has been considered (Kopeliovich et al., 1979).

A mixed model which includes the effects of a single gene, polygenes and their interaction, was proposed by Elkind and Cahaner (1986). They suggested an experimental design comprising of F3 families derived from F2 plants heterozygous for the single gene, in order to estimate the components of the model. This design was used in this study to estimate the effects of the nor gene, polygenes and their interaction on the softness of tomato fruits one and nine days after picking.

\section{MATERIAL AND METHODS}

\section{Experimental populations}

There were three parental populations: (P1) Normal ripening $(+/+)$, soft fruit line 475 originated from a cross between "summer Marmand" and line 70T82-1 (California); (P2) Normal ripening $(+/+)$, soft and high-sugar fruit line 493, 
originated from 76T128-1 (California); (P3) Nonripening (nor/nor), very firm fruit line 864 , an F7 derived from the cross $(66-1 \times 97-1) \times$ (Rutges-nor $\times 97-1$ ). Experimental population No. 1 and No. 2 were comprised of 13 and 21 F3 families obtained by selfing plants heterozygous at the nor locus of the crosses $\mathrm{P} 1 \times \mathrm{P} 3$ and $\mathrm{P} 2 \times \mathrm{P} 3$, respectively.

\section{Experimental procedures}

The experiment was performed in a split plot design in two randomized blocks with one plot of 15 plants for each family per block. In order to identify the nor genotypes of the F3 plants, green fruits were picked from each of them, two weeks prior to the softness measurement experiment, and stored at room temperature $\left(23 \pm 5^{\circ} \mathrm{C}\right)$. Two and four weeks later they were sorted according to their colour, into three groups-red, yellow and greenwhich indicated $+/+$, nor $/+$ and nor/nor, respectively. Four fruits for softness measurement were harvested at "turning stage" (USDA color stage 3 , Anon., 1975) early in the morning, placed in padded boxes and stored at $20 \pm 2^{\circ} \mathrm{C}$. The marking of the flowers at anthesis facilitated the harvest of fruits from plants of nor/nor genotype at a similar chronological age to fruits of nor/t plants.

\section{Measurement of softness}

Universal Test stand Model LTCM-II of Chatillon (Anon., 1982) with DFG10 force measurement head was used in a non-destructive dynamic loading of a fruit placed on its side between two flat plates. Compression speed was $50 \mathrm{~mm} / \mathrm{min}$ for a distance of approximately $0.5 \mathrm{~mm}$, at temperature of $20 \pm 1^{\circ} \mathrm{C}$. Softness was calculated as the ratio between the deformation and the force, and converted to $\mathrm{cm} / \mathrm{kg}$ units. Measurements were made one and nine days after picking, and designated SF1 and SF9, respectively. Fruit diameter, height, weight and final colour were also recorded.

\section{Data analysis}

The interpretation of results followed the outlines described by Elkind and Cahaner (1986). The heterogeneity of slopes was indicated by "SG/Family" plots, in which means of plants of each single gene (SG) genotype (i.e., nor/nor, nor $/+$ and $+/+$ ) were plotted against their family means. The null hypothesis of homogeneous slopes was tested by joint regression analysis, similar to the one used in genotype $\times$ environment interaction
(Yates and Cochran, 1938) by the following model:

$$
Y_{i j}=\mu+\alpha_{i}+Y_{. j}+\beta i\left(Y_{. j}\right)+e_{i j} ;
$$

where $Y_{i j}$ is the mean softness of plants of nor genotype $i$ of family $j$ and $Y_{. j}$ is the mean of family $j ; \mu$ is the general mean; $\alpha_{i}$ is the nor genotype effect; $\beta_{i}$ is the regression coefficient of nor genotype $i ; e_{i j}$ is the error term. $Y_{i j}$ was weighted by its standard error. The regression coefficients, as estimates of multiplicative coefficients (MC), were obtained by a model in which $\mu$ and $Y_{j}$ were dropped. Data processing and some analysis were performed by SAS $(1985 a, b)$ on a VAX 750 .

The Restriction Maximum Likelihood method was used in the analysis of variance by programme $3 \mathrm{~V}$ of BMDP (Dixon et al., 1985). The model used for the analysis was:

$$
\begin{aligned}
Y_{i j k l}= & \mu+F_{j}+B_{k}+(F B)_{j k} \\
& +\alpha_{i}+(\alpha F) i j+C_{i j k l}+e_{i j k l} ;
\end{aligned}
$$

where $Y_{i j k l}$ is the mean fruit softness of plant $l$ in block $k$ of family $j$ with nor genotype $i . \mu$ is the general mean; $F_{j}$ is the effect of family $j ; B_{k}$ is the effect of block $k ;(F B)$ is the between plots effect as well as the family $\times$ block interaction; $\alpha_{i}$ is the nor genotype effect; $(\alpha F)$ is nor $\times$ family interaction; $C_{i j k l}$ is the mean fruit calibre, used as covariate and $e_{i j k l}$ is the effect of plants within nor genotype in a plot. The $\mu$ and $\alpha_{i}$ was regarded as "fixed", while the rest of the effects were "random". Hypothesis testing was accomplished by calculating the difference between $-2 \times \log$ of maximum likelihood of the complete model, and that of a model in which the tested component was absent. This difference is distributed as chi square with 1 degree of freedom (Dixon et al., 1985).

LSF1 and LSF9 were obtained by natural logarithm $(\ln )$ transformation of variables $\mathrm{F} 1$ and SF9, respectively. The MC of a genotype was calculated by anti-log transformation of the genotype effect (the difference between genotype mean and the grand mean) on the log scale. "Net Polygenic Heritability" (NPH), representing the heritability in F3 generation due to polygenes and independent of the single gene effect (Elkind, 1987), was calculated for $\log$ of SF1 according to Cahaner and Hillel (1980).

\section{RESULTS}

\section{Fruit softness 1 day after picking}

$\mathrm{SG} /$ family plots for SF1 are given in fig. 1(a) and 1(b). The solid lines in the plot are those expected in the case of no single gene $\times$ polygenes inter- 


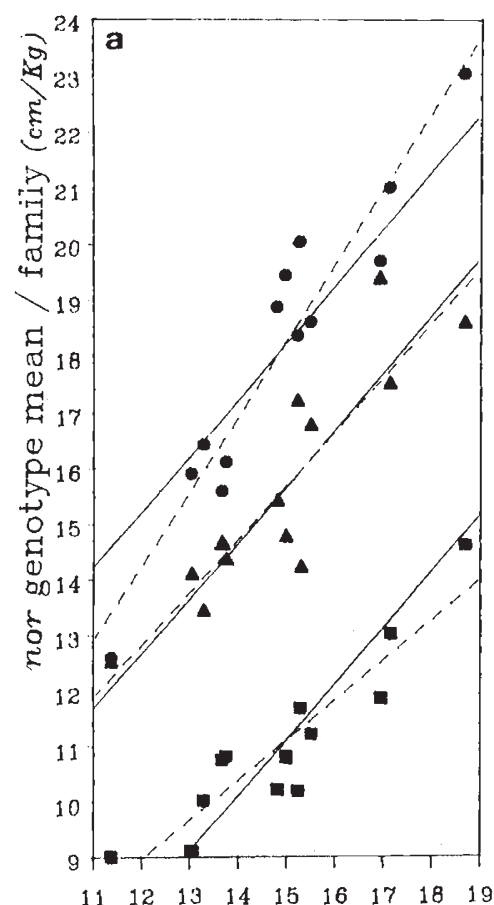

Family mean $(\mathrm{cm} / \mathrm{Kg})$

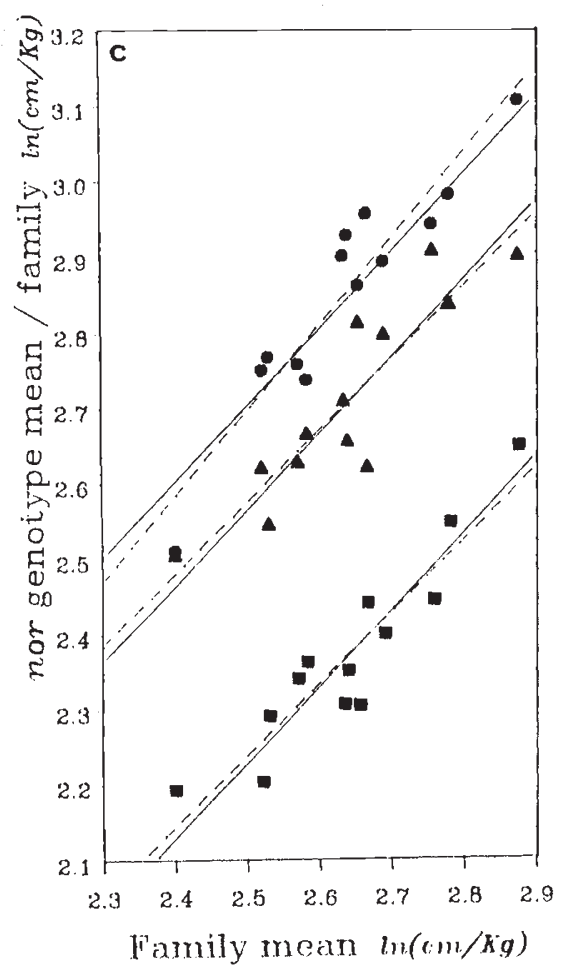

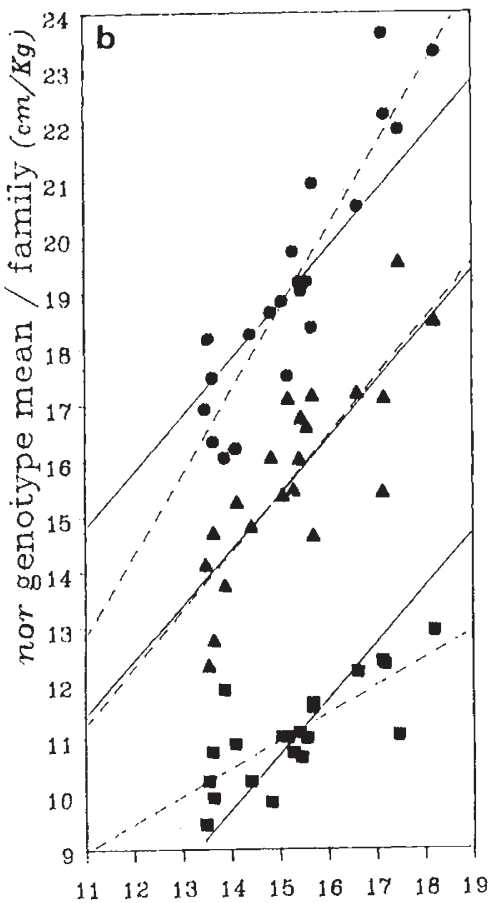

Family mean $(\mathrm{cm} / \mathrm{Kg})$

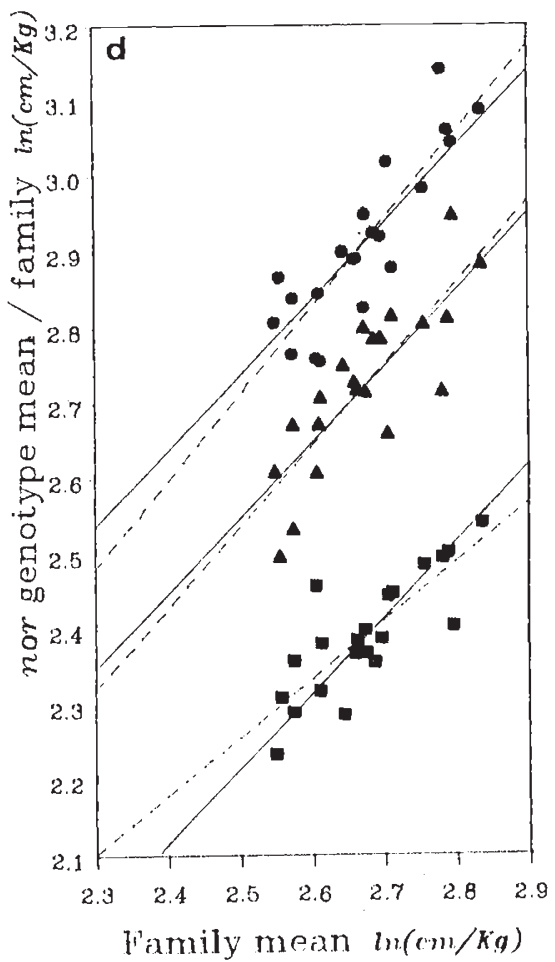

Figure $1 \mathrm{SG}$ /family plots of SF1 (a and b) and LSF1 ( $c$ and d) in populations 1 and 2, respectively. Means within family of the

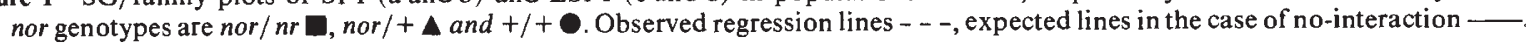


Table 1 ANOVA of joint regression analysis for heterogeneity of slopes of means of single-gene genotype within family on family mean, for SF1 and SF9 $(\mathrm{cm} / \mathrm{kg})$ and their In transformation LSF1 and LSF9

\begin{tabular}{|c|c|c|c|c|c|c|c|c|c|}
\hline \multirow[b]{2}{*}{ Source } & \multirow[b]{2}{*}{$\mathrm{df}$} & \multicolumn{2}{|l|}{ SF1 } & \multicolumn{2}{|l|}{ LSF1 } & \multicolumn{2}{|l|}{ SF9 } & \multicolumn{2}{|l|}{ LSF9 } \\
\hline & & S.S. & $P(F)$ & S.S. & $P(F)$ & S.S. & $P(F)$ & S.S. & $P(F)$ \\
\hline nor genotypes & 2 & 273 & 0.001 & $1 \cdot 28$ & 0.001 & 1508 & 0.001 & $4 \cdot 26$ & 0.001 \\
\hline Families mean & 1 & 130 & 0.001 & 0.52 & 0.001 & 208 & 0.001 & 0.43 & 0.001 \\
\hline Heterogeneity & 2 & 7 & 0.054 & 0.00 & 0.656 & 43 & 0.003 & 0.01 & 0.650 \\
\hline \multicolumn{10}{|l|}{ Population 2} \\
\hline nor genotypes & 2 & 600 & 0.001 & $2 \cdot 51$ & 0.001 & 3936 & 0.001 & $9 \cdot 56$ & 0.001 \\
\hline Families mean & 1 & 120 & 0.001 & 0.42 & 0.001 & 331 & 0.001 & 0.58 & 0.001 \\
\hline Heterogeneity & 2 & 15 & 0.003 & 0.01 & 0.423 & 105 & 0.001 & 0.03 & $0 \cdot 262$ \\
\hline Error & 38 & 41 & & $0 \cdot 17$ & & 194 & & $0 \cdot 38$ & \\
\hline
\end{tabular}

Table 2 Mutiplicative coefficient (MC) and their standard errors (S.E.) for nor genotypes of SF1 and SF9 estimated by joint regression analysis and anti-log transformation

\begin{tabular}{|c|c|c|c|c|c|c|c|c|}
\hline \multirow[b]{3}{*}{ Genotype } & \multicolumn{4}{|c|}{ Joint regression slope } & \multicolumn{4}{|c|}{ Anti-log } \\
\hline & \multicolumn{2}{|l|}{ SF1 } & \multicolumn{2}{|l|}{ SF9 } & \multicolumn{2}{|l|}{$\mathrm{SF} 1$} & \multicolumn{2}{|l|}{ SF9 } \\
\hline & $\mathrm{MC}$ & S.E. & MC & S.E. & $\mathrm{MC}$ & S.E & $\mathrm{MC}$ & S.E. \\
\hline \multicolumn{9}{|c|}{ Population 1} \\
\hline nor/nor & 0.71 & $0 \cdot 28$ & $0 \cdot 37$ & $0 \cdot 36$ & 0.76 & 0.01 & 0.62 & 0.01 \\
\hline nor $/+$ & 0.95 & $0 \cdot 23$ & 0.91 & $0 \cdot 32$ & 1.07 & 0.02 & 1.06 & 0.02 \\
\hline$+1+$ & $1 \cdot 35$ & $0 \cdot 28$ & $1 \cdot 58$ & $0 \cdot 37$ & $1 \cdot 23$ & 0.02 & $1 \cdot 51$ & 0.03 \\
\hline \multicolumn{9}{|c|}{ Population 2} \\
\hline nor/nor & 0.49 & $0 \cdot 20$ & $0 \cdot 28$ & 0.22 & 0.77 & 0.01 & 0.60 & 0.01 \\
\hline nor/t & $1 \cdot 03$ & $0 \cdot 17$ & 0.91 & $0 \cdot 18$ & 1.06 & 0.02 & 1.07 & 0.02 \\
\hline$+1+$ & $1 \cdot 46$ & $0 \cdot 21$ & $1 \cdot 74$ & $0 \cdot 23$ & $1 \cdot 22$ & 0.02 & $1 \cdot 56$ & 0.04 \\
\hline
\end{tabular}

Table 3 Analysis and estimates of variance components $\left(\sigma^{2}\right)$ of the model of LSF1 and LSF9 $(100 \ln (\mathrm{cm} / \mathrm{kg}))$ in F3 families experiment using Restricted Maximum Likelihood method

\begin{tabular}{|c|c|c|c|c|c|c|}
\hline \multirow[b]{2}{*}{ Variance source } & \multicolumn{3}{|c|}{ LSF1* } & \multicolumn{3}{|c|}{ LSF9* } \\
\hline & $\sigma^{2}$ & S.E. & $P\left(\chi^{2}\right)$ & $\sigma^{2}$ & S.E. & $P\left(\chi^{2}\right)$ \\
\hline \multicolumn{7}{|l|}{ Population 1} \\
\hline Between Families & 111 & 52 & 0.0020 & 90 & 45 & 0.0010 \\
\hline Block & 13 & 23 & 0.1253 & 37 & 93 & 0.0503 \\
\hline Family $\times$ Block & 13 & 14 & 0.1302 & 0 & - & 1 \\
\hline nor $\times$ Family & 10 & 12 & $0 \cdot 2017$ & 32 & 20 & 0.0231 \\
\hline Error & 218 & 19 & & 252 & 22 & \\
\hline \multicolumn{7}{|l|}{ Population 2} \\
\hline Between Families & 40 & 17 & 0.0015 & 44 & 27 & 0.0431 \\
\hline Block & 7 & 12 & $0 \cdot 2713$ & 50 & 77 & 0.1175 \\
\hline Family $\times$ Block & 4 & 7 & 0.3428 & 20 & 13 & 0.0255 \\
\hline \multirow[t]{2}{*}{ nor $\times$ Family } & 9 & 8 & $0 \cdot 1936$ & 52 & 19 & 0.0000 \\
\hline & 183 & 13 & & 220 & 16 & \\
\hline
\end{tabular}

* The estimates are in $10,000 \times(\ln (\mathrm{cm} / \mathrm{kg}))^{2}$

S.E. = standard error of the estimate. 
action. The means of the nor/nor and $+/ t$ genotypes within a family deviated from these lines in a non-random fashion. In families with high SF1 mean, the deviations are mostly positive for $+/+$ and negative for nor/nor, and the reverse was found for families with low SF1 mean. This trend indicated a multiplicative interaction between the nor gene and the families (i.e., polygenes). The regression slopes of the three genotypes were heterogeneous in population 2 , and also in population 1 , where $P(F)=0.0544$ was regarded as significant (table 1). The slopes of the regression were smaller than 1 for nor/nor and greater than 1 for $+/+($ table 2$)$.

The multiplicative interaction was incorporated into the model by the use of log transformation. The regression slopes of the nor genotypes of the transformed variable, LSF1, were homogeneous (fig. 1(c) and (d), and table 1) and did not differ from 1 . The multiplicative coefficients (MC) for the effect of the nor gene on the family means, estimated by anti-log, were 0.76 , 1.07 and 1.23 in population 1 for nor/nor, nor $/+$ and $+/+$, respectively. Almost identical MC's were calculated in population 2 (table 2). The SG/family plots of LSF1 in the two populations were also very similar (fig. 1 ). The nor $\times$ family interaction was not significant for LSF1 (table 3), indicating additivity between nor and the families mean (polygenes) after the multiplicative interaction was included in the model.

The estimate of the "between families" variance component for LSF1 in population 2 was half of the estimate of population 1 (table 3 ). The net polygenic heritability (NPH) estimates, based on "within families" and "between families" variance components, were 0.51 and 0.27 for populations 1 and 2, respectively. These values are the ratio of polygenic to total phenotypic variance in $\mathrm{F} 3$ generation.

\section{Fruit softness 9 days after picking}

$\mathrm{SG} /$ family plot for SF9 are presented in fig. 2a and $2 \mathrm{~b}$. Similar to SF1, but more pronounced multiplicative nor $\times$ family interaction was identified in the plot. The regression slopes were heterogeneous (table 1) in the two populations. The slopes were smaller than 1 for nor/nor, and greater than 1 for $+/+$ (table 2$)$.

The multiplicative interaction was incorporated into the model by a log transformation. The slopes of the transformed variable, LSF9, were found to be homogeneous (fig. 2(c), 2(d), and table 1) and did not differ from 1 . The $M C$ for the effect of the nor gene on the family means, estimated by anti-log, were $0.62,1.06$ and 1.51 in nor/nor, nor $/+$ and $+/+$ respectively for population 1 . The MC values for population 2 were almost identical (table 2). The nor $\times$ family interaction was significant for LSF9 (table 3), indicating the presence of random interaction in addition to the multiplicative one. The nature of the interaction was indicated by the random distribution of the nor genotypes within families around the lines of nointeraction (Fig. 2(c), 2(d)). The "between families" variance component for LSF9 in population 1 was twice as large as in population 2 . The reverse situation was found with the "nor $\times$ family" component (table 3 ).

\section{DISCUSSION}

\section{The nature of nor $\times$ polygenes interaction}

\section{Multiplicative interaction}

The nor gene had a multiplicative interaction with the polygenes in both SF1 and SF9. Therefore, MC were estimated for both, and found almost identical in the two populations. The MC of a single gene genotype indicates the effect of the genotype on the family mean over all polygenic combinations. In population 1 , the MC were 0.76 and 1.23 for SF1, and 0.62 and 1.51 for SF9, in the homozygote genotypes nor/nor and $+/+$, respectively. The MC of SF9 deviated from 1 almost twice as much as those of SF1, indicating a larger multiplicative interaction for the former. The MC has no units and it represents the factor for multiplying the family mean in the measured units, i.e., $\mathrm{cm} / \mathrm{kg}$, to yield the expected value of the genotype in the same units. Furthermore, if the only interaction present is a multiplicative one, the ratio between the MCs can be used for predicting the performance of one single-gene genotype based upon the score of its isogenic line with another single-gene genotype. For example, if the ratio of MC of nor/nor to $+/+$ was $1.62(1 \cdot 23 / 0 \cdot 76)$ for SF1, and the score of nor/nor with a specific polygenic constitution (i.e., genome) was $10 \mathrm{~cm} / \mathrm{kg}$, then the predicted value for its isogenic $+/+$ would be $16 \cdot 2 \mathrm{~cm} / \mathrm{kg}$.

Multiplicative interaction between the " $p y$ " gene and polygenes was described by King (1955) for body weight in mice, in which the homozygotes for " $p y$ " were half the weight of their normal litter-mates.

In the present study, MC for SF1 and SF9 were estimated by two methods. Estimates obtained by 


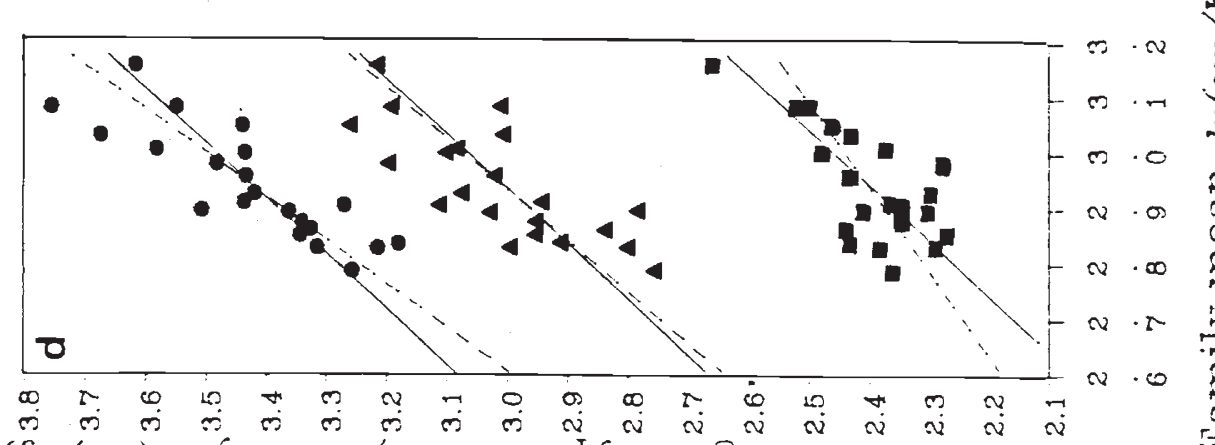

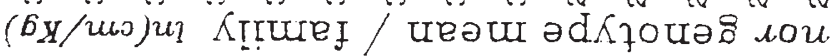

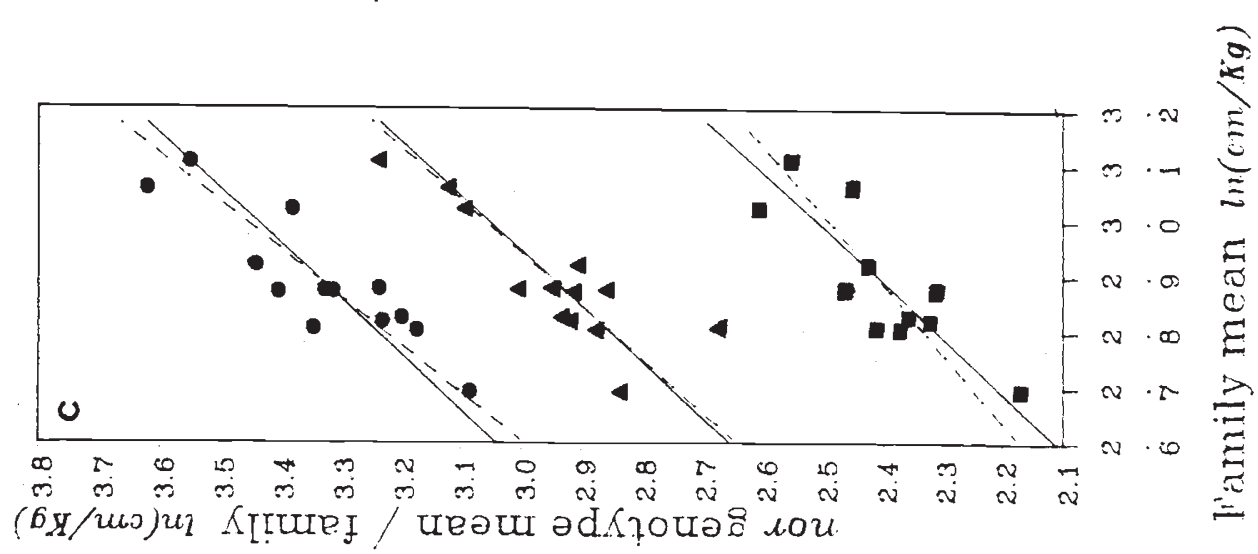

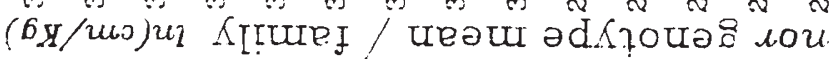

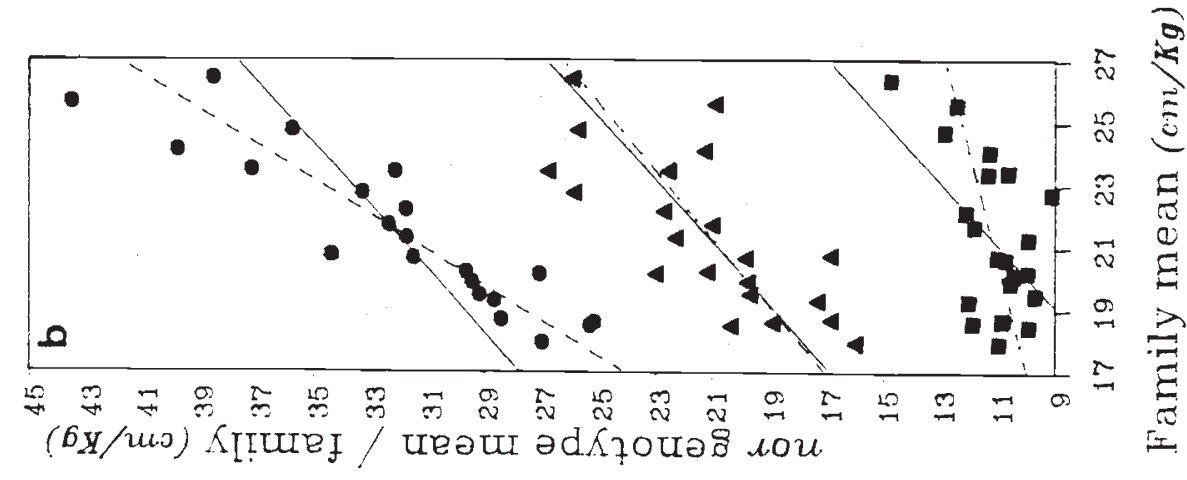

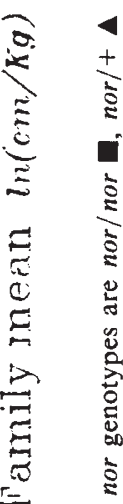

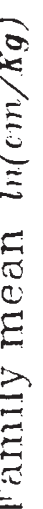

$\stackrel{\Perp}{\leftrightarrows}$

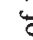

$\stackrel{2}{\bar{\varepsilon}}$

:

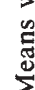

苋

密.

กั

0

ำ

แั้

焉

ㅎ․

을

․․․․

จำ

巳

额

空

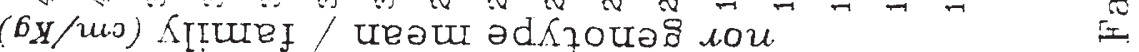

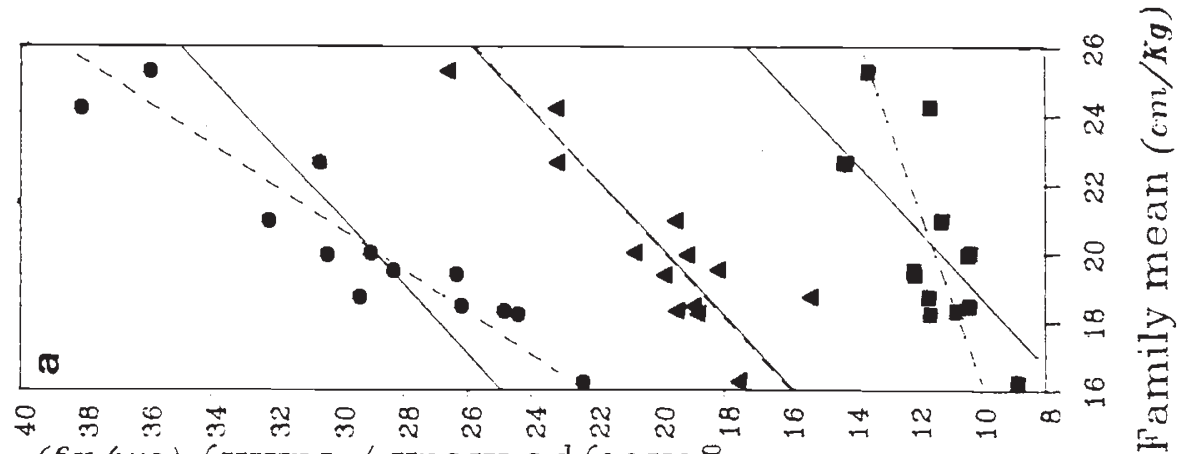


anti-log had smaller standard error than those obtained by regression, e.g., the standard error of regression estimate of MC of SF1 for genotype $+/+$ in population 1 was 0.28 vs. 0.02 of the antilog estimate (table 2). Elkind (1987) simulated multiplicative interaction between a single-gene and polygenes in the $\mathrm{F} 3$ experimental design used in the present study and estimated MC by the two alternative methods. The estimates obtained by anti-log transformation had much smaller variance than those calculated from the regression. The latter was also affected by heterogeneity of variance, a single-gene genotype with larger variance will have greater slope. Therefore, based on smaller S.E. in the experiments, as well as in the simulation study, estimation of MC by anti-log seems to be more reliable than regression. The theoretical aspects of multiplicative interaction between polygenes, and the use of log transformation in quantitative genetic models, were discussed by Horner, Comstock and Robinson (1955). Log transformation was used for tomato fruit weight per locule to achieve adequacy of the additive-dominant model (Powers, 1951).

\section{Multiplicative and random interaction}

Analysis of SF9 indicated the presence of multiplicative as well as random interaction. After the multiplicative interaction was incorporated in the model, a random-nature interaction was also detected (table 3 ). In population 1 the variance component of the interaction was a third of the "between families", whereas, in population 2 it was somewhat greater than the "between families". Therefore, the random interaction between nor and polygenes constitute an important part in the continuous genetic variation of tomato fruit softness 9 days after picking.

The random interaction may result from the fact that some polygenes affecting SF9 were expressed solely in one nor genotype, while other polygenes were expressed in another genotype. Alternatively, linkage between polygenes and the nor locus will also result in such interaction.

The variance estimates of the random interaction provide information about the expected deviations from the single-gene and the family effects. For example, in a family from population 2 with mean LSF9 of $2.95 \ln (\mathrm{cm} / \mathrm{kg})$ the value for nor $/+$ genotype is expected to be 3.02 (the effect of the genotype was $0 \cdot 07$, table 4 ). However, the random interaction variance was $0.0052 \ln (\mathrm{cm} /$ $\mathrm{kg})^{2}$ (table 3 ), therefore, the interaction standard deviation was $0.072 \ln (\mathrm{cm} / \mathrm{kg})$. Thus, 95 per cent
Table 4 Mean and standard error (S.E.) of the nor genotypes of LSF1 and LSF9 $(\ln (\mathrm{cm} / \mathrm{kg}))$ in two populations

\begin{tabular}{|c|c|c|c|c|}
\hline \multirow[b]{2}{*}{ Genotype } & \multicolumn{2}{|l|}{ LSF1 } & \multicolumn{2}{|l|}{ LSF9 } \\
\hline & Mean & S.E. & Mean & S.E. \\
\hline \multicolumn{5}{|c|}{ Population 1} \\
\hline All & $2 \cdot 64$ & 0.03 & $2 \cdot 89$ & 0.04 \\
\hline nor/nor & $2 \cdot 37$ & 0.04 & $2 \cdot 42$ & 0.07 \\
\hline nor $/+$ & $2 \cdot 71$ & 0.04 & $2 \cdot 95$ & 0.07 \\
\hline$+1+$ & $2 \cdot 85$ & 0.04 & $3 \cdot 30$ & 0.07 \\
\hline \multicolumn{5}{|c|}{ Population 2} \\
\hline All & $2 \cdot 68$ & 0.02 & 2.95 & 0.04 \\
\hline nor/nor & $2 \cdot 42$ & 0.03 & $2 \cdot 43$ & 0.06 \\
\hline nor/t & $2 \cdot 74$ & 0.03 & 3.02 & 0.06 \\
\hline$+1+$ & $2 \cdot 88$ & 0.03 & $3 \cdot 40$ & 0.06 \\
\hline
\end{tabular}

of the families are expected to be distributed between $2 \cdot 87$ to $3 \cdot 15 \ln (\mathrm{cm} / \mathrm{kg})( \pm 2$ S.D.). Interpreting the random interaction in the softness units by anti-log transformation of two standard deviations $(0 \cdot 14)$ gives $1 \cdot 15$. This actually gives a multiplicative factor that is somewhat similar to $\mathrm{MC}$, and can be used to calculate the random distribution borders due to the interaction for each family. Furthermore, using MC ratio to predict the expression of one nor genotype based on its isogenic SF9 value, will have even larger deviation because the random interaction acts independently on both genotypes. For example, if the ratio of MC of nor/t to +/t of SF9 is $0.69(1.07 / 1.56)$ and the softness is $30 \mathrm{~cm} / \mathrm{kg}$, the predicted softness for $n o r /+$ will be $20.7 \mathrm{~cm} / \mathrm{kg}$. But, due to random interaction, with 2 S.D. on the log scale of $0 \cdot 20$ which gave a factor of 1.23 on the softness scale, the distribution interval for 95 per cent of the families will be between 16.9 and $25.4 \mathrm{~cm} / \mathrm{kg}$ assuming no experimental error, and between 16.6 and $25.7 \mathrm{~cm} / \mathrm{kg}$ including the experimental error.

This study demonstrates the utilization of detection and estimation of random interaction in predicting the effects of single-gene and polygenes on a quantitative trait. Furthermore, estimates of single-gene effects obtained from an experiment such as F3 families can be useful even in the presence of interaction, while estimates based on isogenic lines are relevant only to specific genetic background studied.

\section{The effect of nor on softness}

The rank of means of the three genotypes of nor for SF1 and SF9, as was found in this study, is 
consistent with findings of others (Brady et al., 1982; McGlasson et al., 1983; Ng and Tigchelaar, 1977). A more comprehensive comparison between these studies and the present one was not made because of differences in genetic backgrounds as well as in measuring methods and units.

The effect of nor on the ripening process (Brady et al., 1982) is probably responsible for the effect of the gene on the softness in SF1 and SF9 measurements. It is known that the ripening process commences a few days before the "turning" stage (Davies and Hobson, 1981), at which the fruits for the experiment were harvested. This could also explain the increase in the effect of nor during ripening.

\section{Net Polygenic Heritability (NPH)}

The NPH estimated for LSF1 in this work were 0.51 and 0.26 for populations 1 and 2, respectively. If the heritability was to be estimated from the same F3 families by the standard procedure, i.e., ignoring the gene nor, the heritability estimates would be 0.78 and 0.68 , respectively. The relatively large effect of nor caused the increase in the heritability as well as the reduced difference between the populations. NPH provides an accurate estimate for the gain expected by selection of the polygenes, and it is not affected by the genetic variation due to the single-gene, which has heritability of 1 .

\section{Utilization of the nor gene in tomato breeding}

Since fruits of nor/nor plants do not ripen at all (horticulturally), only the utilization of the heterozygote genotype $($ nor $/+$ ) for extending the shelf life, indicated by SF9 will be discussed. Mean SF9 of fruits of nor $/+$ plants was about 30 per cent lower than that of fruits of normal plants $(+/+)$ from the same family (MC 1.07 vs. 1.56 , respectively, table 2 ). Furthermore, one can speculate that the increase in the $\mathrm{MC}$ from 1 to 9 days (SF1 to SF9) also indicates that the MC of nor/+ fruits after additional storage period will be even greater. Extending the shelf life based on these results involves the combined use of the nor/t+ genotype with polygenes. The presence of multiplicative interaction indicates that the expected effect of the nor gene will be greater in a soft genetic background. However, overall extended shelf life might be obtained by a combination of polygenes for low SF9 expressed in all the nor genotypes in addition to polygenes that reduce SF9 specifically in the nor/ + genotype. Softness after nine days (SF9) of less than $21 \mathrm{~cm} / \mathrm{kg}$ can be obtained only with nor/ + and family mean less than $21 \mathrm{~cm} / \mathrm{kg}$ (Figure 2a, 2b). But, within these families the one with the lowest family mean does not have the lowest SF9 for nor/+ (fig. 2(a)). At present, the nor gene is not widely used in breeding because of its adverse effect on fruit colour and flavour (Kopeliovitch et al., 1979). Future studies on the effect of the nor gene and polygenes on flavour and on colour accumulation in the fruit may increase the importance of this gene in tomato breeding.

\section{CONCLUSIONS}

The present study illustrates the ability of an experiment comprised of $\mathrm{F} 3$ families derived from F2 plants heterozygous for a single-gene, to simultaneously detect the effects of the single-gene, polygenes and their interaction on a quantitative trait. Furthermore, this design allows the nature of this interaction to be characterized, i.e. multiplicative, random and a combination of the two. The detection and characterization of a single-gene $x$ polygenes interaction are important aspects in studying gene expression. It can also assist in studying genes transferred by advanced molecular techniques, since they can be easily identified and are inherited as single-genes. The results of this study also indicate that the nor gene can be useful in extending the shelf life of tomato, by using the nor/+ genotype in an optimal polygenic constitution.

Acknowedgements We wish to thank Dr S. Oman for statistical advice, E. Dax for her technical assistance and E. Zoltan-Glick for her contribution to the graphical presentation.

\section{REFERENCES}

AL-FAlluJi, A., TINKLEIN, D. H. AND LAMBETH, V. N. 1982. Inheritance of pericarp firmness in tomato by generation mean analysis. HortScience, 17, 763-764.

ANON. 1975. Color classification requirements in tomatoes USDA Visual Aid TM-L-1 (the John Henri Company: Lansing, Michigan.)

ANON. 1982. Universal test stands models LTC and LTCMII instruction manual. John Chatillon and Sons, NY.

BRADY, C. J., MELDRUM, S. K., McGLASSON, W. B. AND ZAINON, M. A. 1982. Differential accumulation of the molecular forms of polygalacturonase in tomato mutants. J. of Food Biochemistry, 7, 7-14.

CAHANER, A. AND HILLEL, J. 1980. Estimating heritability and genetic correlation between traits from generations $F 2$ and F3 of self-fertilizing species: a comparison of three methods. Theor. Appl. Genet., 53, 33-38. 
DAVIES, J. N. AND HOBSON, C: E. 1981. The constituents of tomato fruit-the influence of environment, nutrition and genotype. CRC Crit. Rev. Food Sci. Nutr. 15, 205-280.

DIXON, W. J., BROWN M. B., ENGELMAN, L., FRANE, J. W., HILL, M. A., JENNRICH, R. A. AND TOPPREK, J. D. 1985. BMDP Statistical Software. University of California Press, Berkeley.

ELKIND, Y. AND CAHANER, A. 1986. A mixed model for the effects of single gene, polygenes and their interaction on quantitative traits. 1. The model and experimental design. Theor. Appl. Genet., 72, 377-383.

ELKIND, Y. 1987. Ph.D. Thesis, Hebrew University of Jerusalem.

EL-SAYED, M. N. K., ERICKSON, H. T. AND TOMES, M. L. 1966. Inheritance of tomato fruit firmness. Proc. Amer. Soc. Hort. Sci., 89, 523-527.

HORNER, T. E., COMSTOCK, R. E. AND ROBINSON, H. F. 1955. Non-allelic gene interactions and the interpretation of quantitative genetic data. North Carolina Agricultural Experiment Station, Tec. Bul., 118.

KING, J. W. B. 1955. Observations on the mutant "pygmy" in the house mouse. J. Genet., 53, 487-497.
KOPELIOVITCH, E., RABINOWITCH, H. D., MIZRAHI, Y. AND KEDAR N. 1979. The potential of ripening mutants for extending the storage life of tomato fruit. Euphytica, 28, 99-104.

MCGLASSON, W. B., SUMEGHY, J. B., MORRIS, L. L., MCBRIDE, R. L., BEST, D. J. AND TIGCHELAAR, E. R. 1983. Yield and evaluation of F1 tomato hybrids incorporating the nonripening nor gene. Aust. J. Exp. Agric. Anim. Husb., 23, 106-112.

NG, T. AND TIGCHELAAR, E. R. 1977. Action of non-ripening nor mutant on fruit ripening of tomato. J. Amer. Soc. Hort. Sci., 102, 504-509.

POWERS, L. 1951. Gene analysis by the partitioning method when interactions of genes are involved. Bot. Gaz., 113, $1-23$.

SAS INSTITUTE INC. 1985a. SAS User Guide: Basics, Version 5 edition. Cary NC: SAS Institute Inc. $1290 \mathrm{pp}$.

SAS INSTITUTE INC. 1985b. SAS User Guide: Statistics, Version 5 edition. Cary NC: SAS Institute Inc. 956pp.

YATES, F. AND COCHRAN W. G. 1938. The analysis of groups of experiments. J. Agric. Sci., 28, 556-558. 